\title{
Photophysical Properties of Amino- and Dimethylamino Salicylates in Neat and Binary Solvent Mixtures
}

\author{
Marek Aleksiejew, Marek Józefowicz, and Janina R. Heldt \\ Institute of Experimental Physics, University of Gdańsk, Wita Stwosza 57, 80-952 Gdańsk, Poland \\ Reprint requests to Dr. J. R. H.; Fax: 048-58341-31-75; E-mail: fizjh@univ.gda.pl
}

Z. Naturforsch. 60a, 655 - 666 (2005); received June 1, 2005

The solvation characteristic of 2-methoxy-4-aminobenzoic acid methyl ester (MABAE) and 2methoxy-4-dimethylaminobenzoic acid methyl ester (MDABAE) in the $\mathrm{S}_{0}, \mathrm{~S}_{1}$ (LE) and $\mathrm{S}_{1}$ (ICT) states has been determined by means of solvatochromic shifts in neat and binary solvent mixtures. The multiple linear regression analysis of Kamlet et al. indicates that non-specific dielectric dipoledipole and specific hydrogen-bonding interactions play almost an equal role in defining the position of the absorption and fluorescence maxima. On the basis of the performed analysis of normalized solvatochromic shifts, it has been shown that both solutes are preferentially solvated. For cyclohexane-ethanol $(\mathrm{CH}-\mathrm{EtOH})$ binary mixtures the preferential solvation characteristics in the $\mathrm{S}_{0}$, $\mathrm{S}_{1}(\mathrm{LE})$ and $\mathrm{S}_{1}(\mathrm{ICT})$ states are determined predominantly by the hydrogen-bonding interactions. For both molecules under study the electric dipole moment in the $\mathrm{S}_{0}, \mathrm{~S}_{1}(\mathrm{LE})$ and $\mathrm{S}_{1}(\mathrm{ICT})$ states as well as the outer-sphere solvent reorganization energy $\left(\lambda_{\text {out }}\right)$, intramolecular reorganization energy $\left(\lambda_{\text {in }}\right)$, and destabilization energy $\left(E_{\text {dest. }}\right)$ have been determined.

Key words: Binary Solvents; Reorganization Energy; Aminosalicylates.

\section{Introduction}

In series of papers $[1-4]$ competitive deexcitation pathways of several aminosalicylates were studied. It was shown, that some of them possess two or three radiation modes. Modes are related to: the normal locally excited state emission $\mathrm{S}_{1}(\mathrm{LE}) \rightarrow \mathrm{S}_{0}$; the excited state intramolecular proton transfer tautomer emission $\mathrm{S}_{1}^{\prime}(\mathrm{PT}) \rightarrow \mathrm{S}_{0}^{\prime}(\mathrm{PT})$; and the twisted intramolecular charge-transfer emission $\mathrm{S}_{1}^{\prime}(\mathrm{ICT}) \rightarrow \mathrm{S}_{0}^{\prime}(\mathrm{ICT})$. The two additional emission modes correspond to different forms of the parent molecule (conformers created in a chemical reaction occurring in the excited state). Their fluorescence bands are situated on the long wavelength side of the normal fluorescence. Generally it is accepted that the photoinduced intramolecular charge transfer (ICT) reaction of donor-acceptor compounds occurring in the excited state results in:

(i) a rotational relaxation toward twist of the dimethylamino group (donor) with respect to the aromatic ring, benzonic acid methyl ester (acceptor), leading to a so called twisted intramolecular charge transfer (TICT) state [5-7];

(ii) a conformational change arising from rehybridization of dimethylamino nitrogen (as proposed by Zachariasse et al. $[8,9])$, which in the $-\mathrm{N}\left(\mathrm{CH}_{3}\right)_{2}$ group has $\mathrm{sp}^{3}$ like structure and converts to a planar $\mathrm{sp}^{2}$ structure to achieve a planar intramolecular charge transfer (PICT) state without twisting or a wagged intramolecular charge transfer (WICT) state.

Following the TICT reaction, the change of electron density of a light absorbing molecule is manifested through a difference between the dipole moment in the electronic ground and excited states. That implies a different solute-solvent molecule interaction in both states. The solute-solvent molecule interaction arises either from the isotropic interaction of the solute dipole moment with the reaction field induced in the nearest surrounding solvent molecules (first solvation shell) or from the short range anisotropic interactions, e.g., hydrogen bonds, between the solute molecule with one or more solvent molecules in its first solvation shell. Mostly both interactions coexist in the solution of donor-acceptor compounds. They cause a solvatochromic shift of the absorption, normal $\left(\mathrm{F}_{1}\right)$ and the intra- or intermolecular charge transfer $\left(\mathrm{F}_{2}\right)$ fluorescence bands.

In many papers $[1-4,8-10]$, it has been shown that the above interaction processes can be modulated, due to their dependence on the solvent polarity of aprotic and protic solvents. Hydrogen bonds between solute and solvent molecules lead to more complicated 
interactions, i. e., decreasing of the fluorescence quantum yield, giving further red shift of $F_{1}$ and $F_{2}$ fluorescence bands and cause their wider broadening relative to measurements in aprotic solvents of the same polarity $[11,12]$.

In our previous papers $[3,4,13,14]$, steady-state and time-resolved spectroscopic data were used to assign the three emission modes of aminosalicylates, benzanilides and $\alpha$-, $\beta$-naphthanilides, employing molecular selection for studying the influence of substituent effects and polarity changes on band shifts and the fluorescence band halfwidth (fwhm full width at half maximum). This paper reports results of extended spectroscopic studies of 2-methoxy4-aminobenzoic acid methyl ester (MABAE) and 2methoxy-4-dimethylaminobenzoic acid methyl ester (MDABAE) in several neat aprotic and protic solvents and binary mixed solvents, e.g., cyclohexanetetrahydrofuran (CH-THF), cyclohexane-ethanol $(\mathrm{CH}-$ $\mathrm{EtOH})$ and acetonitrile-ethanol (AcN-EtOH). The results of spectroscopic measurements are used to obtain information about the influence of the solvation processes, in particular the intermolecular hydrogen bonds influence on the spectroscopic properties of studied molecules. The results of spectroscopic measurements are analyzed according to the theoretical model for the continuum dielectric solvent given by Oshika [15], Lippert [16], and Bilot and Kawski [17,18]. Taking advantage of the multiple linear regression analysis approach of Kamlet et al. [19], the empirical solvent polarity parameters, the Tafts $\pi^{*}$ values, characterizing dipolar interaction between solute and solvent molecules, and $\alpha$ and $\beta$ values, representing the hydrogen bond donating (HBD) and accepting (HBA) ability of the solvent [20] have been determined. According to the procedure of Marcus [21], using the FranckCondon energies of absorption $\left(\tilde{v}_{\mathrm{A}}\right)$ and fluorescence $\left(\tilde{v}_{\mathrm{F}}^{\mathrm{LE}}, \tilde{v}_{\mathrm{F}}^{\mathrm{ICT}}\right)$ maxima, the solvent destabilization energy $\left(E_{\text {dest. }}\right)$ and intramolecular reorganization energy $\left(\lambda_{\text {in }}\right)$ and outer-sphere $\left(\lambda_{\text {out }}\right)$ solvent reorganization energy have been calculated for all solvents used.

\section{Experimental}

2-Methoxy-4-aminobenzoic acid methyl ester (MABAE) and 2-methoxy-4-dimethylaminobenzoic acid methyl ester (MDABAE) have been synthesized according to Gormin [1,2]. The solvents cyclohexane $(\mathrm{CH})$, methylcyclohexane $(\mathrm{McH}), 2,2,4-$ trimethylpentane (Tri), diethyl ether (DE), butyl acetate (BAc), 1,2-dichlorobenzene (DClB), ethyl acetate (EtAc), methylene chloride (MC), tetrahydrofuran (THF), hexanol (Hex), ethanol (EtOH), acetonitrile $(\mathrm{AcN})$, methanol $(\mathrm{MeOH})$ were purchased from Aldrich Chemical Co; they were spectral and HPLC grade. Additionally, all solvents used were checked in a fluorescence apparatus for the lack of fluorescent impurities in the wavelength ranges of interest. Before its use, $\mathrm{CH}$ was distilled from a sodium-potassium amalgam to ensure that it was anhydrous. The MABAE and MDABAE compounds were checked chromatographically. The concentration of the studied solution was ca. $1.25 \cdot 10^{-4} \mathrm{M}$.

The absorption and fluorescence spectra were recorded using, respectively, a Shimadzu UV-2401PC spectrophotometer and a Shimadzu RF-5301 spectrofluorometer with $3.0 \mathrm{~nm}$ band width in excitation and $5.0 \mathrm{~nm}$ band width in emission. The luminescence spectra have been corrected for the spectral response of a photomultiplier (Hamamatsu R-928). All measurements have been performed at $293 \mathrm{~K}$.

\section{Results and Discussion}

\subsection{Spectroscopic Studies of Neat Solutions}

The absorption and fluorescence spectra of the compounds under study in neat solvents, such as cyclohexane (nonpolar), tetrahydrofuran and acetonitrile (polar aprotic) and ethanol (polar protic), are shown on Figure 1. The long wavelength absorption spectrum possesses two maxima, at $270 \mathrm{~nm}$ and $300 \mathrm{~nm}$ for MABAE and $280 \mathrm{~nm}$ and $305 \mathrm{~nm}$ for MDABAE. The increase of the solvent polarity shifts the absorption bands of both molecules to longer wavelengths and changes their intensities, e. g., in protic solvents the absorption band at lowest energy, ca. $300 \mathrm{~nm}$, has higher intensity than that at $270(280) \mathrm{nm}$, and additionally the blurred vibrational structure is lost.

The fluorescence spectra of both molecules in nonpolar solvents are similar and possess one band which is assigned as $S_{1}(L E) \rightarrow S_{0}$ transition. The fluorescence spectrum of MABAE in polar solvents possesses a similar shape, except in $\mathrm{EtOH}$, where it is broadened and more red-shifted in comparison to that measured in the aprotic solvent AcN. It is more important to note here that the polar character of ethanol is smaller than that of acetonitrile.

In polar aprotic and protic solvents, the fluorescence spectrum of MDABAE possesses two bands, 
Table 1. The wavenumbers of the absorption, $\tilde{v}_{\mathrm{A}}$, and fluorescence, $\tilde{v}_{\mathrm{F}}^{\mathrm{LE}}$ and $\tilde{v}_{\mathrm{F}}^{\mathrm{ICT}}$, band maxima of MABAE and MDABAE in solvents.

\begin{tabular}{|c|c|c|c|c|c|c|c|c|}
\hline \multirow[b]{2}{*}{ No. } & \multirow[b]{2}{*}{ Solvent } & \multirow[b]{2}{*}{ Symbol } & \multirow[b]{2}{*}{$f(\varepsilon, n)$} & \multicolumn{2}{|c|}{ MABAE } & \multicolumn{3}{|c|}{ MDABAE } \\
\hline & & & & $\begin{array}{c}\tilde{v}_{\mathrm{A}} \\
{\left[\mathrm{cm}^{-1}\right]}\end{array}$ & $\begin{array}{c}\tilde{v}_{\mathrm{F}}^{\mathrm{LE}} \\
{\left[\mathrm{cm}^{-1}\right]}\end{array}$ & $\begin{array}{c}\tilde{v}_{\mathrm{A}} \\
{\left[\mathrm{cm}^{-1}\right]}\end{array}$ & $\begin{array}{c}\tilde{v}_{\mathrm{F}}^{\mathrm{LE}} \\
{\left[\mathrm{cm}^{-1}\right]}\end{array}$ & $\begin{array}{c}\tilde{v}_{\mathrm{F}}^{\mathrm{ICT}} \\
{\left[\mathrm{cm}^{-1}\right]}\end{array}$ \\
\hline 1 & cyclohexane & $\mathrm{CH}$ & 0 & 33762 & 31056 & 32786 & 30202 & \\
\hline 2 & methylcyclohexane & $\mathrm{McH}$ & 0 & & & 32794 & 30221 & \\
\hline 3 & 2,2,4-trimethylpentane & Tri & 0.002 & & & 32846 & 30285 & \\
\hline 4 & diethyl ether & $\mathrm{DE}$ & 0.166 & 33277 & 30395 & 33113 & 29851 & 25126 \\
\hline 5 & butyl acetate & $\mathrm{BAc}$ & 0.171 & 33239 & 30395 & & & \\
\hline 6 & 1,2-dichlorobenzene & $\mathrm{DClB}$ & 0.187 & & & 31898 & 28506 & 24773 \\
\hline 7 & ethyl acetate & EtAc & 0.200 & 33249 & 30303 & 32329 & 28986 & 22660 \\
\hline 8 & methylene chloride & MC & 0.205 & & & 32258 & 28571 & 23641 \\
\hline 9 & tetrahydrofuran & THF & 0.217 & 33070 & 30212 & 32283 & 28902 & 22920 \\
\hline 10 & hexanol & Hex & 0.245 & & & 32895 & 28409 & 20619 \\
\hline 11 & ethanol & $\mathrm{EtOH}$ & 0.288 & 32679 & 29586 & 31890 & 28770 & 20760 \\
\hline 12 & acetonitrile & $\mathrm{AcN}$ & 0.305 & 33161 & 30030 & 32055 & 28169 & 21170 \\
\hline 13 & methanol & $\mathrm{MeOH}$ & 0.308 & & & 32051 & 28571 & 20000 \\
\hline
\end{tabular}

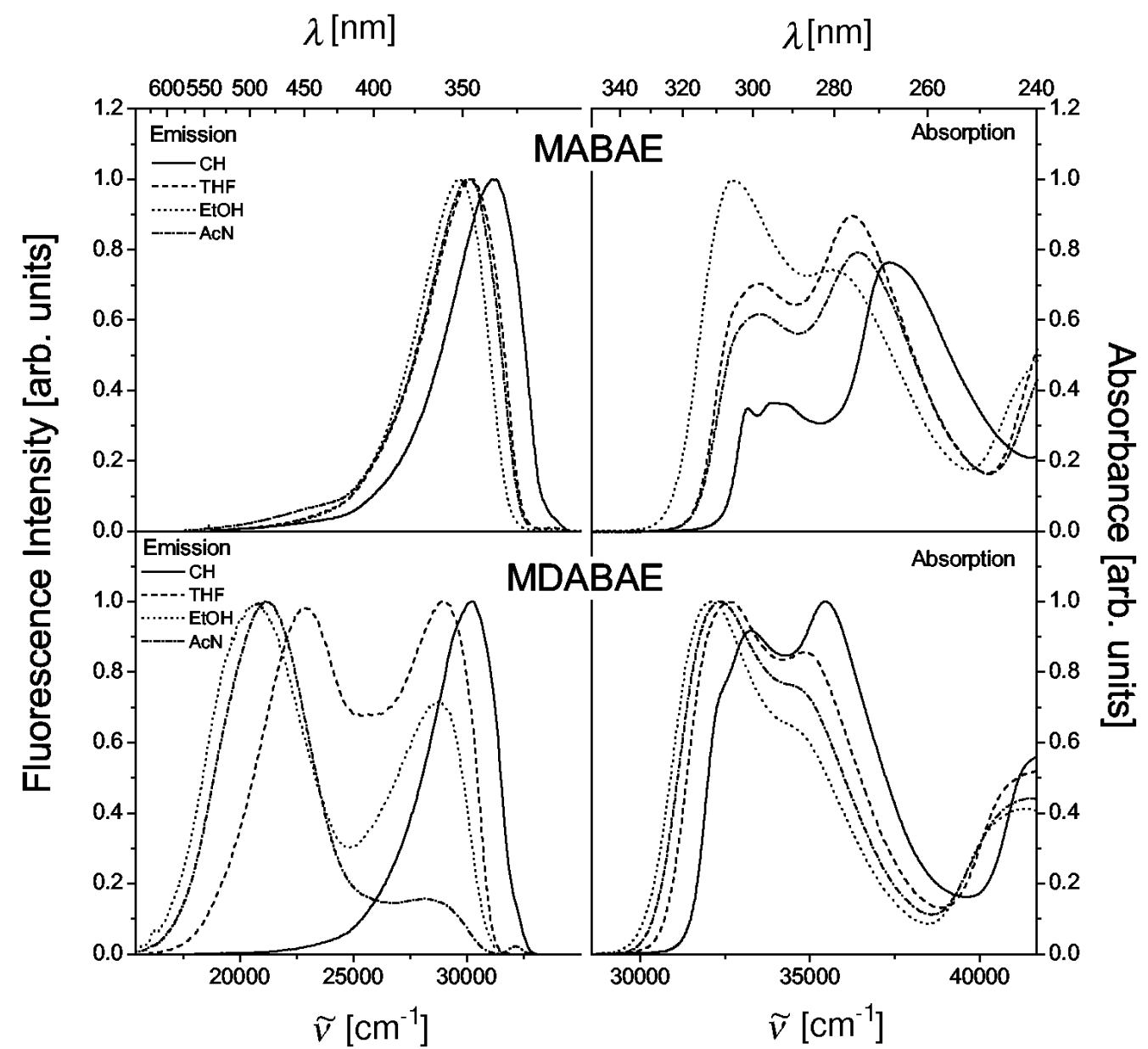

Fig. 1. Absorption and fluorescence spectra of MABAE and MDABAE in representative solvents of different polarity. 
MABAE

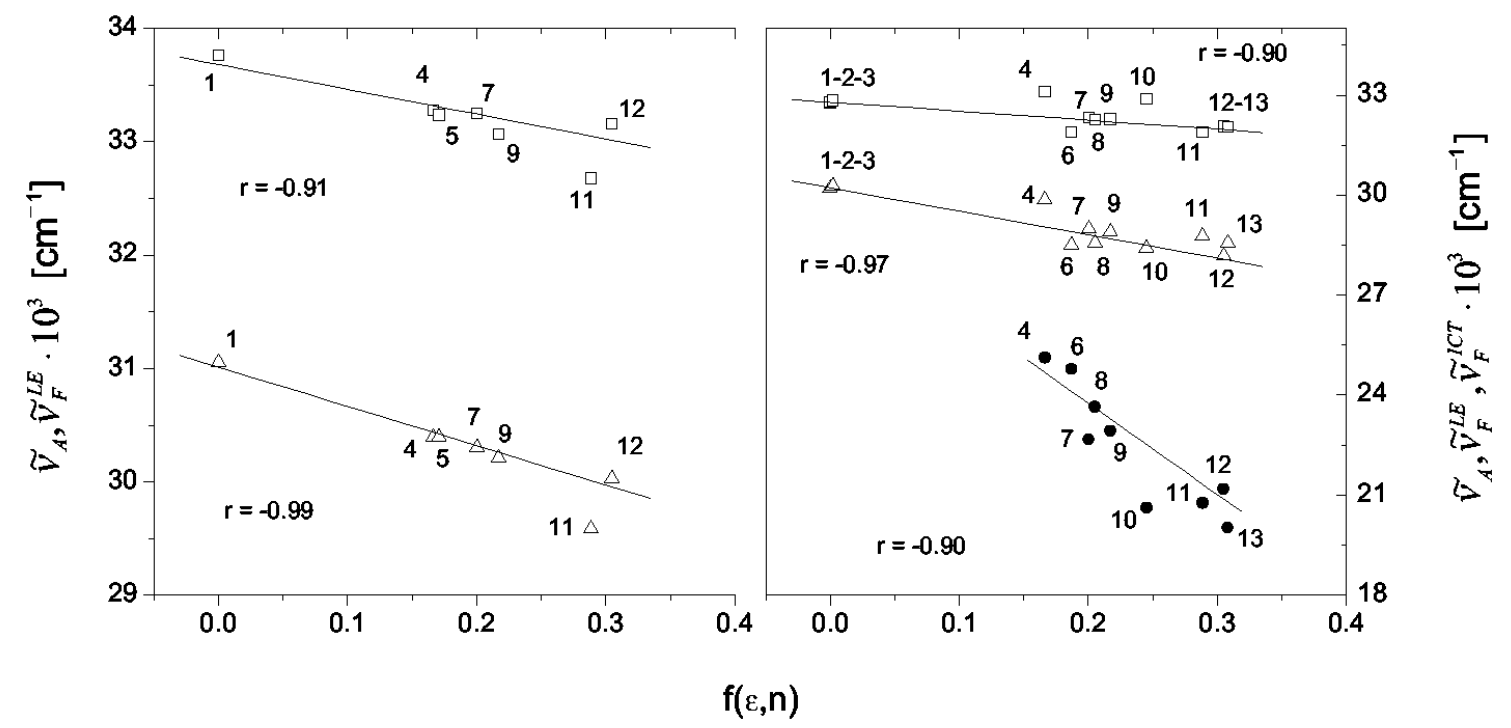

Fig. 2. Absorption $(\square)$ and fluorescence ( $\triangle$ LE; $\bullet$ ICT) band maxima of MABAE and MDABAE vs. the Lippert polarity function $f(\varepsilon, n)$. The numbers on experimental points indicate the solvents as given in Table 1 .

i. e., the normal fluorescence, F(LE), and ICT fluorescence, $\mathrm{F}(\mathrm{ICT})$, bands. The wavelength maxima of both bands $\left(\tilde{v}_{\mathrm{F}}^{\mathrm{LE}}\right.$ and $\left.\tilde{v}_{\mathrm{F}}^{\mathrm{ICT}}\right)$ depend on the solvent polarity (see Fig. 1 and Table 1). As can be seen in Fig. 2, a linear plot between the wavenumbers of the absorption and fluorescence maxima vs. the Lippert polarity function $f(\varepsilon, n)$ is obtained. The dotted line indicates the best fit of the obtained experimental data. The correlation coefficient $r$ does not differ much from 1.0 and is larger than 0.9 .

The changes of $\tilde{v}_{\mathrm{A}}$ and $\tilde{v}_{\mathrm{F}}^{\mathrm{LE}}, \tilde{v}_{\mathrm{F}}^{\mathrm{ICT}}$ values noted for the used solvents (see Table 1) arise from either general dipole-dipole and/or specific interactions between the solute and solvent molecules [22,23]. Some general information concerning the kind of interaction characteristic of the solute molecules in neat solvents can be received from the multiple linear regression approach of Kamlet et. al. [19,20], which determines the correlation of the absorption and emission energies with indexes of the solvent polarizability/polarity $\pi^{*}$, and $\alpha, \beta$, representing the hydrogen bond donating (HBD) and accepting (HBA) ability of the solvent, respectively. The multiple linear regression has been performed according to

$$
\tilde{v}_{\mathrm{A}, \mathrm{F}}=\tilde{v}^{0}+A \pi^{*}+B \alpha+C \beta
$$

Using (1) and the respective experimental data assembled in Table 1, the following equations have been obtained:

$$
\begin{array}{ll}
\text { MABAE: } & \tilde{v}_{\mathrm{A}}=v_{\mathrm{A}}^{0}-399( \pm 95) \pi^{*}-233( \pm 78) \alpha-816( \pm 121) \beta, \quad(r=0.981), \\
& \tilde{v}_{\mathrm{F}}=v_{\mathrm{F}}^{0}-884( \pm 174) \pi^{*}-466( \pm 143) \alpha-709( \pm 221) \beta, \quad(r=0.968), \\
\text { MDABAE: } & \tilde{v}_{\mathrm{A}}=v_{\mathrm{A}}^{0}-839( \pm 34) \pi^{*}-505( \pm 27) \alpha-16( \pm 43) \beta, \quad(r=0.998), \\
& \tilde{v}_{\mathrm{F}}^{\mathrm{LE}}=v_{\mathrm{F}}^{0}-3017( \pm 142) \pi^{*}-567( \pm 112) \alpha-874( \pm 182) \beta, \quad(r=0.994) .
\end{array}
$$

Since the long wavelength fluorescence band arises from the emission of the ICT conformer, the multiple linear regression analysis has also been used to correlate $\tilde{v}_{\mathrm{F}}^{\text {ICT }}$ with the solvent polarizability indexes: $\pi^{*}, \alpha$ and $\beta$. For the ICT fluorescence band the following regression equation has been obtained:

$$
\tilde{v}_{\mathrm{F}}^{\mathrm{ICT}}=v_{\mathrm{F}}^{0}+6777( \pm 6027) \pi^{*}-4143( \pm 1331) \alpha+6813( \pm 5268) \beta, \quad(r=0.89) .
$$



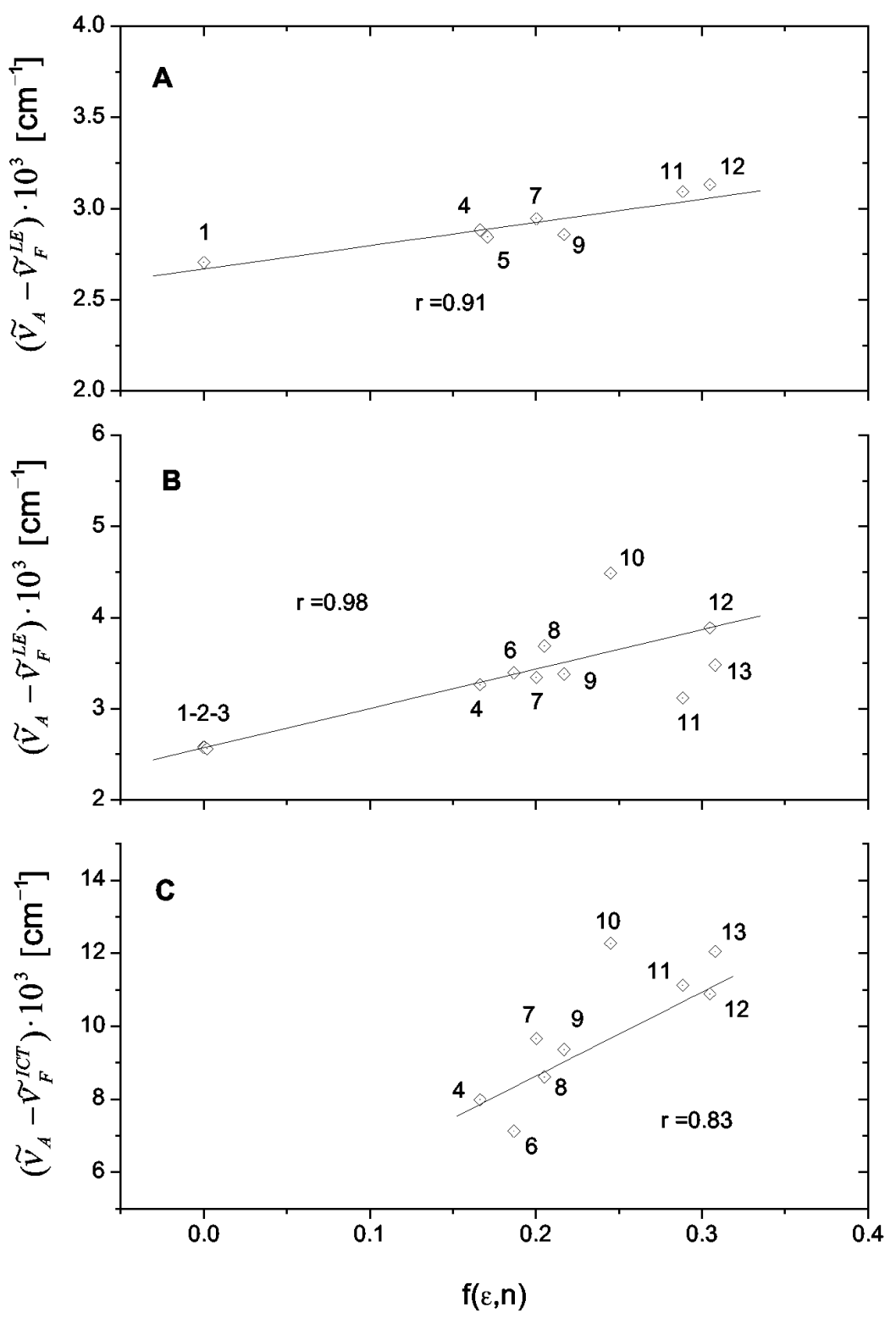

Fig. 3. The Stokes shift $\delta \tilde{v}_{\mathrm{AF}}=\tilde{v}_{\mathrm{A}}-$ $\tilde{v}_{\mathrm{F}}^{\mathrm{LE}}\left(\tilde{v}_{\mathrm{F}}^{\mathrm{ICT}}\right)$ values vs. the Lippert polarity function $f(\varepsilon, n)$ of MABAE (panel A) and MDABAE (panels B and $\mathrm{C}$ ). The numbers at the experimental points indicate the solvent as given in Table 1.

It is worth noticing that the correlation coefficients of the absorption (2a) and (3a) and emission (2b), (3b) and $(3 c)$ regression equations are almost equal to unity. This points to a good correlation of the experimental $\tilde{v}_{\mathrm{A}}, \tilde{v}_{\mathrm{F}}^{\mathrm{LE}}$ and $\tilde{v}_{\mathrm{F}}^{\mathrm{ICT}}$ data with the polarizability parameters of Kamlet et al. The analysis of the above equations proves:

- The solvation of MABAE is mainly determined by a hydrogen bond accepting the ability $(\beta)$ with the solvent. The dipolar interaction $\left(\pi^{*}\right)$ and hydrogenbond donation $(\alpha)$ processes play an about two and three times smaller role $\left(\pi^{*} / \beta=0.49, \alpha / \beta=0.29\right)$. The ratio of the regression coefficients obtained for the emission spectra equals $\beta / \alpha=1.52, \beta / \pi^{*}=0.80$ and $\alpha / \pi^{*}=0.53$ and points out that the position of the fluorescence spectrum mostly depends on the dipoledipole dielectric interaction $\left(\pi^{*}\right)$ and the specific HBA $(\beta)$ interaction.

- The position of the electronic absorption spectrum of MDABAE depends mostly on the nonspecific dielectric interaction $\left(\pi^{*}\right)$ and, to a smaller degree, on $\operatorname{HBD}(\alpha)$ processes $\left(\alpha / \pi^{*}=0.60\right)$. The HBA strength 
Table 2. Calculated (Theoret.) and experimental (Exp.) values of the dipole moments in Debyes of MABAE and MDABAE in the ground $S_{0}$ and singlet $S_{1}(L E), S_{1}(I C T)$ states.

\begin{tabular}{|c|c|c|c|c|}
\hline \multirow[b]{2}{*}{ State } & \multicolumn{2}{|r|}{ MABAE } & \multicolumn{2}{|r|}{$\overline{M D A B A E}$} \\
\hline & Exp. & Theoret. & Exp. & Theoret. \\
\hline$a_{0}[\mathrm{~m}]$ & & $2.387 \cdot 10^{-10}$ & & $2.48 \cdot 10^{-10}$ \\
\hline & & 4.862 (AM1) & & 5.130 (AM1) \\
\hline $\mathrm{S}_{0}$ & & 4.557 (PM3 CISD) & & 4.590 (PM3 CISD) \\
\hline$S_{1}(L E)$ & 6.2 & & 7.6 & \\
\hline $\mathrm{S}_{1}(\mathrm{ICT})$ & & & 11.7 & \\
\hline
\end{tabular}

exhibits a very insignificant influence $\left(\beta / \pi^{*} \cong 0.02\right)$. The position of the normal (LE) fluorescence band is mostly influenced by the nonspecific dielectric interaction $\left(\pi^{*}\right)$. The ratio of the regression coefficients of $\alpha$ and $\beta$ to $\pi^{*}$ equals 0.19 and 0.29 , respectively. Comparing them to respective regression coefficients obtained from the absorption spectra, it follows that hydrogen-bonding interactions, peculiarly the HBA, play a significant role in shifts of the normal fluorescence spectrum.

- In the (3c) the regression coefficients of $\pi^{*}, \alpha$ and $\beta$ are determined with little accuracy. They point out that the position of the ICT fluorescence band of MD$\mathrm{ABAE}$ is determined by the specific and nonspecific interaction of solute-solvent molecules in the same ratio $\left(\pi^{*} / \alpha=-1.64, \pi^{*} / \beta=0.99, \alpha / \beta=0.61\right)$.

\subsection{Dipole Moment Determination}

Figure 3 shows a graphical presentation of the Stokes shift of the normal $\tilde{v}_{\mathrm{A}}-\tilde{v}_{\mathrm{F}}^{\mathrm{LE}}=\delta \tilde{v}_{\mathrm{AF}}^{\mathrm{LE}}$ and intramolecular charge transfer band $\tilde{v}_{\mathrm{A}}-\tilde{v}_{\mathrm{F}}^{\mathrm{ICT}}=\delta \tilde{v}_{\mathrm{AF}}^{\mathrm{ICT}}$ of MABAE and MDABAE vs. the Lippert polarity function $f(\varepsilon, n)$. As can be seen in Fig. 3, a linear dependence on $f(\varepsilon, n)$ is fulfilled with a correlation coefficient almost equal to unity. The obtained data are disregarded for both molecules under study dissolved in polar protic solvents.

According to Bakshiev [24], Kubota and Mataga [25], and Kawski [18] the solvatochromic Stokes shift of various solutions can be well described by the expressions

$$
\begin{aligned}
& \delta \tilde{v}_{\mathrm{AF}}^{\mathrm{LE}, \mathrm{ICT}}=\frac{\left(\mu_{\mathrm{e}}-\mu_{\mathrm{g}}\right)^{2}}{2 \pi \varepsilon_{0} h c a_{0}^{3}} f(\varepsilon, n), \\
& f(\varepsilon, n)=\frac{\varepsilon-1}{2 \varepsilon+1}-\frac{n^{2}-1}{2 n^{2}+1},
\end{aligned}
$$

where $\mu_{\mathrm{e}}$ and $\mu_{\mathrm{g}}$ are the permanent dipole moments of the molecule in the excited and ground state, respectively, $a_{0}$ is the effective radius of the Onsager cavity. The constants: $\varepsilon_{0}, h$, and $c$ are the permitivity of vacuum $\left(8.85 \cdot 10^{-12} \mathrm{C} \mathrm{V}^{-1} \mathrm{~m}^{-1}\right)$, Planck's constant $\left(6.626 \cdot 10^{-34} \mathrm{~J} \mathrm{~s}\right)$ and the velocity of the light $\left(3.0 \cdot 10^{8} \mathrm{~m} \mathrm{~s}^{-1}\right)$. In (4) $\varepsilon$ is the static dielectric constant and $n$ the refractive index of the solvent. Using a linear regression to fit the data collected in Table 1, the difference between $\mu_{\mathrm{e}}$ and $\mu_{\mathrm{g}}$ has been determined. In order to get the value of $\mu_{\mathrm{e}}$, the dipole moment of both molecules in the $\mathrm{S}_{0}$ state was calculated, using the CaChe WS 5.04 computer program and AM1 [26] and PM3 [27] methods, which involve a complete geometry optimization of the ground state. The values of the Onsager cavity radius $a_{0}, \mu_{\mathrm{g}}$ and $\mu_{\mathrm{e}}$ of the title compounds are collected in Table 2 . Analyzing the data assembled in Table 2, it follows that the dipole moment of both molecules in the $\mathrm{S}_{1}$ (LE) state increases by about $30 \%$ in comparison to its value in the $S_{0}$ state. The dipole moment of the MDABAE molecule in the $\mathrm{S}_{1}$ (ICT) state is two times larger than that in the $\mathrm{S}_{0}$ state. This result agrees with data obtained for similar molecules $[6,18]$.

\subsection{Reorganization Energy}

It is well-known [1-6] that intramolecular charge transfer reactions accompanied with conformational changes of solute molecules in the excited electronic state are noticed in the appearance of dual fluorescence. Conformational changes of the molecules in the emitting assembly cause a spectral inhomogenity of the fluorescent solution. This effect is observed as a fluorescence band broadening. According to Marcus' theory (in details presented in [21]), the halfwidth of the ICT fluorescence band, $\Delta \tilde{v}_{1 / 2}$, is related to the sum of the inner-sphere intramolecular reorganization en$\operatorname{ergy},\left(\lambda_{\text {in }}\right)$, and the outer-sphere reorganization energy, $\left(\lambda_{\text {out }}\right)$, by

$$
\left(h c \Delta \tilde{v}_{1 / 2}\right)^{2} \approx 8(\ln 2)\left(2 k T \lambda_{\text {out }}+\lambda_{\text {in }} h c \tilde{v}\right) .
$$

The inner-sphere reorganization energy includes rotational and vibrational energy of the solute for which $h v<k T$ and $h v>k T$. The outer-sphere reorganization energy is associated with low frequency motions causing reorientation of molecules in the solvation shell. $\lambda_{\text {out }}$ depends on the dipolar interaction between solute and solvent molecules. Taking the Onsager model into consideration, $\lambda_{\text {out }}$ is given by [21]

$$
\lambda_{\text {out }}=\frac{\left(\mu_{\mathrm{e}}-\mu_{\mathrm{g}}\right)^{2}}{4 \pi \varepsilon_{0} a_{0}^{3}} f(\varepsilon, n),
$$

where all constants have the meaning as in (4). 


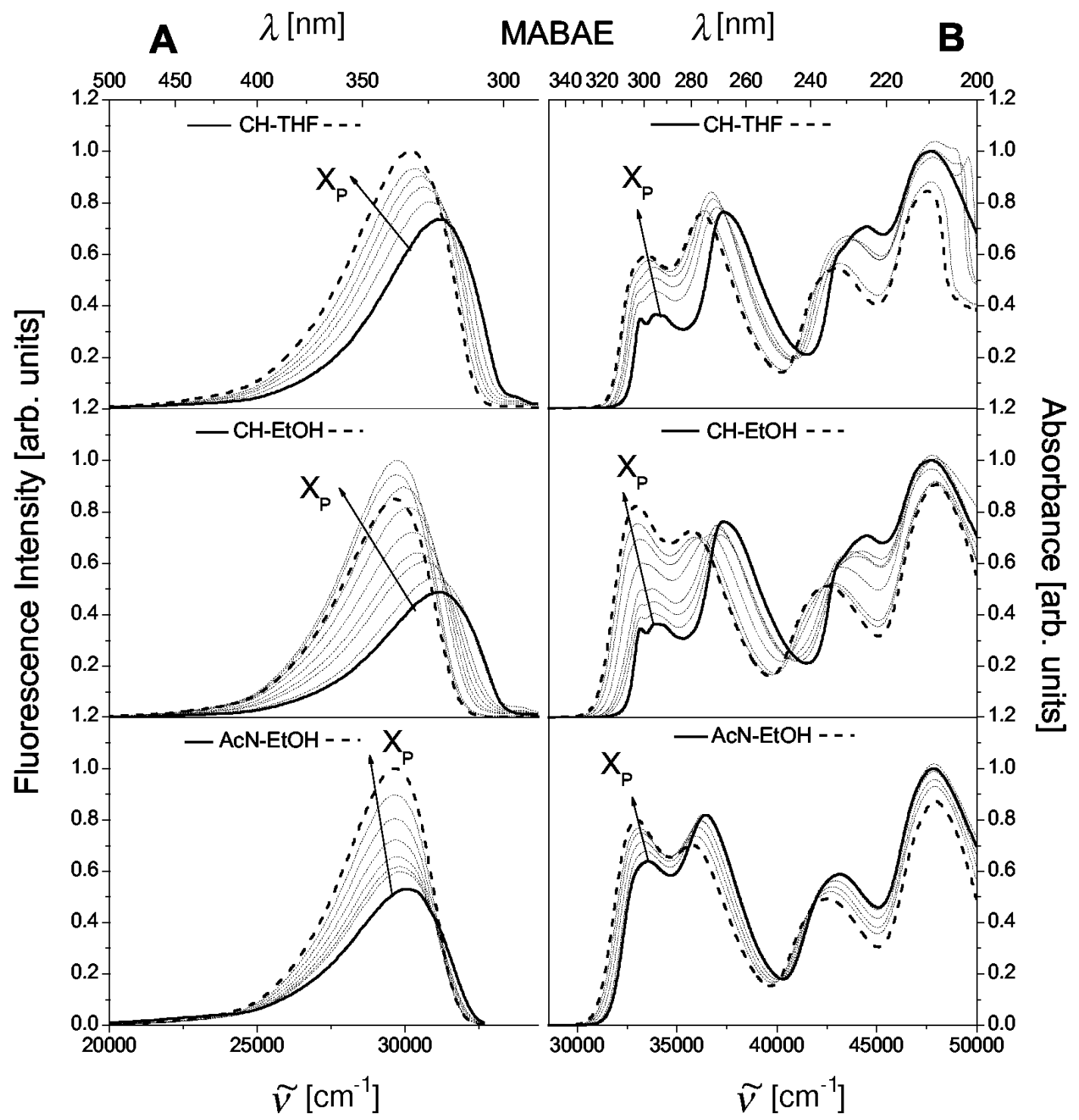

Fig. 4. Fluorescence and absorption spectra of MABAE in neat solvents. $\mathrm{CH}, \mathrm{THF}, \mathrm{AcN}$ and EtOH and their mixtures at different mole fractions $x_{\mathrm{p}}$ of THF and EtOH. The arrows point to increasing mole fraction $x_{\mathrm{p}}$.

According to Marcus' theory [21], and Mataga and Kubota [25], the total destabilization/reorganization energy is given by

$$
E_{\text {dest. }}=h c\left(\tilde{v}_{\mathrm{A}}^{\max }-\tilde{v}_{\mathrm{F}}^{\max }\right)=2\left(\lambda_{\text {out }}+\lambda_{\text {in }}\right)
$$

Using the $\mu_{\mathrm{e}}$ values assembled in Table 2 and (6), the outer-sphere reorganization energy $\lambda_{\text {out }}$ for both molecules was calculated. The $\lambda_{\text {in }}$ values for the respective solutions are obtained by use of (7) and collected in Table 3.
Analyzing the data presented in Table 3, it follows:

- The Stokes shift, $\delta \tilde{v}_{\mathrm{AF}}$, data of MABAE in a neat solvent shows a linear dependence on the Lippert polarity function, $f(\varepsilon, n)$ (see Fig. 3A). The destabilization energy, $E_{\text {dest. }}$, as well as the outer, $\lambda_{\text {out }}$, and inner, $\lambda_{\text {in }}$, reorganization energies at the same time undergo only small changes (see Table 3 ). It must be marked that $\lambda_{\text {out }} \ll \lambda_{\text {in }}$, and they correspond to the vibration respective frequencies $\tilde{v}_{\text {out }} \cong 200 \mathrm{~cm}^{-1}$ and $\tilde{v}_{\text {in }} \cong 1340 \mathrm{~cm}^{-1}$. The inner-sphere reorganization en- 
Table 3. Stokes shifts, $\delta \tilde{v}_{\mathrm{AF}}\left[\mathrm{cm}^{-1}\right]$, reorganization energies, $\lambda_{\text {out }}$ and $\lambda_{\text {in }}$, and destabilization energies, $\mathrm{E}_{\mathrm{dest}}[\mathrm{eV}]$, of MABAE and MDABAE in the used solvents.

\begin{tabular}{|c|c|c|c|c|c|c|c|c|c|c|}
\hline \multirow[b]{2}{*}{ No. } & \multirow[b]{2}{*}{ Solvent } & \multirow[b]{2}{*}{$f(\varepsilon, n)$} & \multicolumn{4}{|c|}{ MABAE } & \multicolumn{4}{|c|}{ MDABAE } \\
\hline & & & $\delta \tilde{v}_{\mathrm{AF}}$ & $\lambda_{\text {out }}$ & $\lambda_{\text {in }}$ & $E_{\text {dest. }}$ & $\delta \tilde{v}_{\mathrm{AF}}$ & $\lambda_{\text {out }}$ & $\lambda_{\text {in }}$ & $E_{\text {dest. }}$ \\
\hline 1 & $\mathrm{CH}$ & 0 & 2706 & 0 & 0.170 & 0.170 & 2584 & 0 & 0.160 & 0.160 \\
\hline 2 & $\mathrm{McH}$ & 0 & & & & & 2574 & 0 & 0.160 & 0.160 \\
\hline 3 & Tri & 0.002 & & & & & 2561 & 0.001 & 0.158 & 0.159 \\
\hline 4 & $\mathrm{DE}$ & 0.166 & 2882 & 0.013 & 0.166 & 0.179 & & & & \\
\hline 5 & BAc & 0.171 & 2844 & 0.014 & 0.162 & 0.176 & & & & \\
\hline 6 & DClB & 0.187 & & & & & 3392 & 0.048 & 0.162 & 0.210 \\
\hline 7 & EtAc & 0.200 & 2946 & 0.016 & 0.167 & 0.183 & 3343 & 0.052 & 0.155 & 0.207 \\
\hline 8 & $\mathrm{MC}$ & 0.205 & & & & & 3687 & 0.053 & 0.176 & 0.229 \\
\hline 9 & THF & 0.217 & 2858 & 0.017 & 0.170 & 0.177 & 3381 & 0.056 & 0.154 & 0.210 \\
\hline 10 & Hex & 0.245 & & & & & 4486 & 0.063 & 0.152 & 0.278 \\
\hline 11 & $\mathrm{EtOH}$ & 0.288 & 3093 & 0.023 & 0.170 & 0.192 & 3120 & 0.074 & 0.119 & 0.193 \\
\hline 12 & $\mathrm{AcN}$ & 0.305 & 3132 & 0.024 & 0.170 & 0.194 & 3886 & 0.079 & 0.161 & 0.240 \\
\hline 13 & $\mathrm{MeOH}$ & 0.308 & & & & & 3480 & 0.080 & 0.136 & 0.216 \\
\hline
\end{tabular}

ergy of MABAE does not depend on the kind of solvent (see Table 3 ).

- The Stokes shift values, $\delta \tilde{v}_{\mathrm{AF}}$, of the MDABAE molecule in nonpolar solvents are smaller than those in polar aprotic and protic solutions $\left(2570 \mathrm{~cm}^{-1} \mathrm{vs}\right.$. $3340 \mathrm{~cm}^{-1}$ ). A similar behaviour show data of the destabilization energies, $E_{\text {dest. }}$. It must be noted that the inner-sphere reorganization energy, $\lambda_{\text {in }}$, is constant with in the error limits of its determination and equals to $(0.157 \pm 0.007) \mathrm{eV}$ or $1266 \mathrm{~cm}^{-1}$. The outer-sphere reorganization energy, $\lambda_{\text {out }}$, increases simultaneously with the increase of $f(\varepsilon, n)$ (see Table 3 ).

\subsection{Binary Solvent Mixtures}

The following binary solvent mixtures were used: $\mathrm{CH}-\mathrm{THF}, \mathrm{CH}-\mathrm{EtOH}$ and $\mathrm{AcN}-\mathrm{EtOH}$, i. e., the mixtures of nonpolar-weak polar aprotic, nonpolar-polar protic, and polar aprotic-polar protic solvents both with comparable polarity. Figures 4 and 5 show the absorption and fluorescence spectra of MABAE and MDABAE in the named binary mixtures, obtained for different mole fractions, $x_{\mathrm{p}}$, of THF or EtOH. The mole fraction of the polar component in the binary solution characterizes the microenvironmental dielectric constant $f\left(\varepsilon_{\mathrm{np}}\right)=x_{\mathrm{p}} f\left(\varepsilon_{\mathrm{p}}\right)+\left(1-x_{\mathrm{p}}\right) f\left(\varepsilon_{\mathrm{n}}\right)$. As can be seen in Figs. 4 and 5 , the absorption and fluorescence spectra of both molecules under study are shifted to a longer wavelength, and undergo intensity changes by increasing the polar component of binary mixtures. The fluorescence spectra of MDABAE in the used binary mixtures are more complex, since besides the solvatochromic shift, an ICT band appears by adding a small quantity of a polar solvent.
From Figs. 4 and 5 it follows that the absorption spectra of both molecules change in the same way by adding the polar component to the neat $\mathrm{CH}$ or $\mathrm{AcN}$ solvent, i. e., the absorption maxima are bathochromically shifted in $\mathrm{CH}$-THF and $\mathrm{CH}-\mathrm{EtOH}$ mixtures, and the vibronic structure of the longwavelength absorption is lost. Also, the intensity of their bands are interchanged, i.e., the band at $\lambda \cong 270 \mathrm{~nm}$ with the band at $\lambda \cong 285 \mathrm{~nm}$. The MABAE fluorescence spectrum in binary mixtures consists of the LE band only. It is bathochromically shifted and shows higher intensity with increasing the concentration of the polar aprotic and protic component of the binary mixtures.

Figures 6 and 7 present graphically the observed changes of the normalized solvatochromic shifts (NSS) of the absorption, $\Delta v_{\mathrm{sol}}^{\mathrm{N}}(\mathrm{A})$, and fluorescence, $\Delta \tilde{v}_{\mathrm{sol}}^{\mathrm{N}}(\mathrm{F})$, spectra determined for different mole fractions, $x_{\mathrm{p}}$, of the polar component. In these figures the intensity changes of the fluorescence LE and ICT band are presented, as well. The intensities due to the used experimental condition, are proportional to the relative fluorescence quantum yield of the solution under study. Analyzing the data graphically presented in Figs. 6A and 7A, it follows:

- The normalized solvatochromic shifts of the absorption and fluorescence bands of both molecules in the used binary solvents show a negative deviation from linearity, indicating evidence for dielectric enrichment [28]. The exception is for the absorption spectrum of MABAE and MDABAE in the AcN-EtOH binary solvent mixture, where the linear dependence of $\Delta v_{\mathrm{sol}}^{\mathrm{N}}$ (A) an $x_{\mathrm{p}}$ is fulfilled.

- The rapid change (a very sudden decrease) of $\Delta \tilde{v}_{\text {sol }}^{\mathrm{A}}(\mathrm{A})$ and $\Delta \tilde{v}_{\text {sol }}^{\mathrm{A}}(\mathrm{F})$, which takes place in the $\mathrm{CH}$ - 


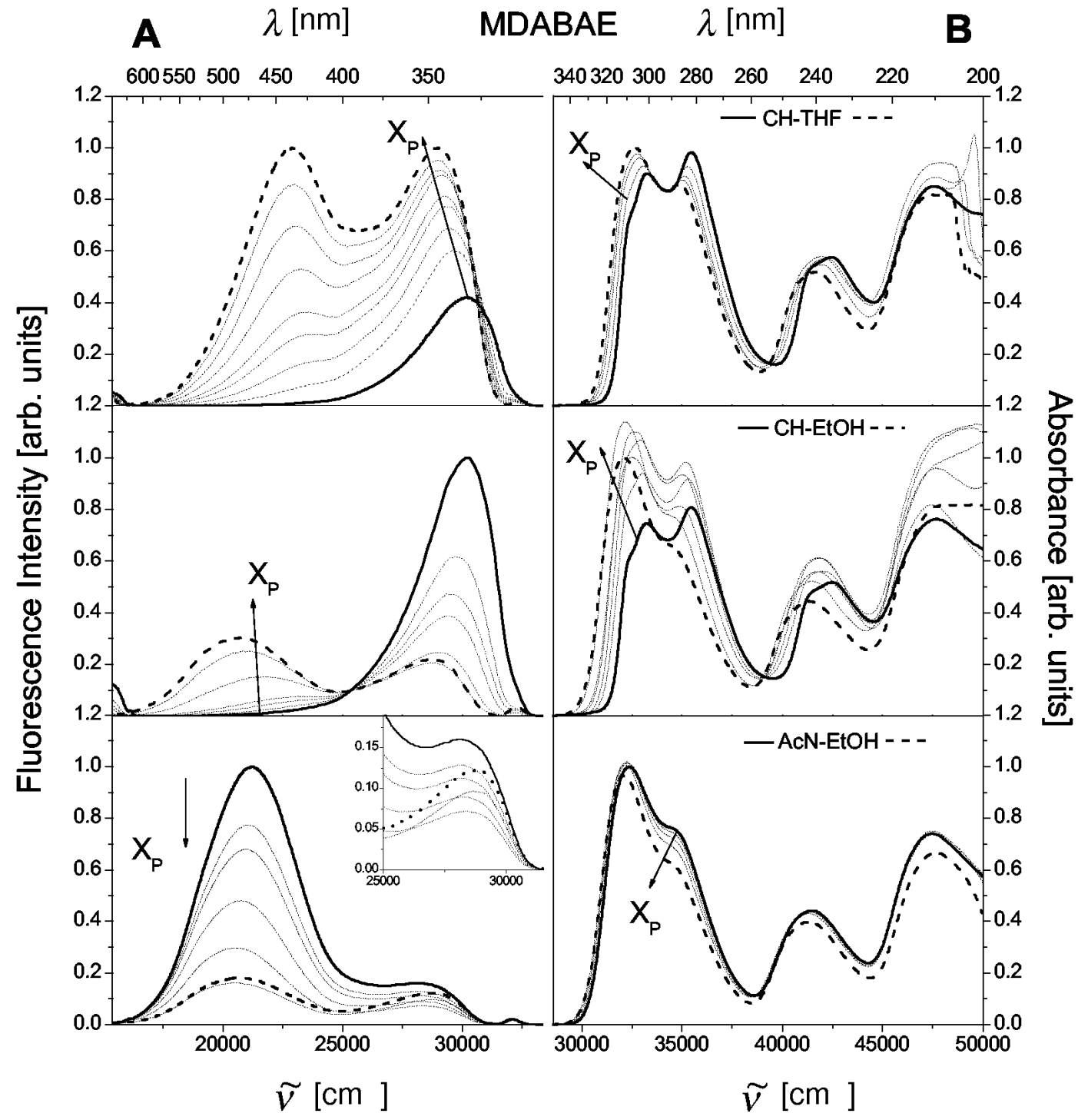

Fig. 5. Absorption and fluorescence spectra of MDABAE in neat solvents. $\mathrm{CH}$, THF, AcN and EtOH and their binary mixtures at different mole fractions $x_{\mathrm{p}}$, of THF and EtOH. The arrows point to the increase of $x_{\mathrm{p}}$.

EtOH solution at very low concentration, is understandable in terms of hydrogen-bonding between the solute and EtOH molecules. This statement is confirmed by higher values of the outer-sphere reorganization energy in comparison to that of nonpolar and polar aprotic neat solvents (see Table 3).

- The different courses of $\Delta \tilde{v}_{\mathrm{sol}}^{\mathrm{N}}(\mathrm{A}), \Delta \tilde{v}_{\mathrm{sol}}^{\mathrm{N}}(\mathrm{F}(\mathrm{LE}))$ and $\Delta \tilde{v}_{\text {sol }}^{\mathrm{A}}(\mathrm{F}(\mathrm{ICT}))$ vs. $x_{\mathrm{p}}$ point out that the interaction of the MDABAE molecule with a solution of AcN$\mathrm{EtOH}$ molecules is different in each electronic state, i. e., $S_{0}, S_{1}(\mathrm{LE})$ and $S_{1}$ (ICT).
The above named findings are reflected by the relative fluorescence quantum yield $\Phi_{\mathrm{F}}(\mathrm{LE})$ and $\Phi_{\mathrm{F}}(\mathrm{ICT})$ changes noticed changing the concentration of the polar component in the binary solution. Figures $6 \mathrm{~B}$ and $7 \mathrm{~B}$ show graphically the $\Phi_{\mathrm{F}}(\mathrm{LE})$ and $\Phi_{\mathrm{F}}(\mathrm{ICT})$ vs. $x_{\mathrm{p}}$ dependencies. The obtained curves can be approximated by two or three straight lines which characterize the fill up of the solvation shell by the polar (THF, panel 1) or polar protic (EtOH, panel 2,3) molecules. As it follows from Figs. 6B and 7B, the relative quantum yield of the MABAE molecule increases with in- 


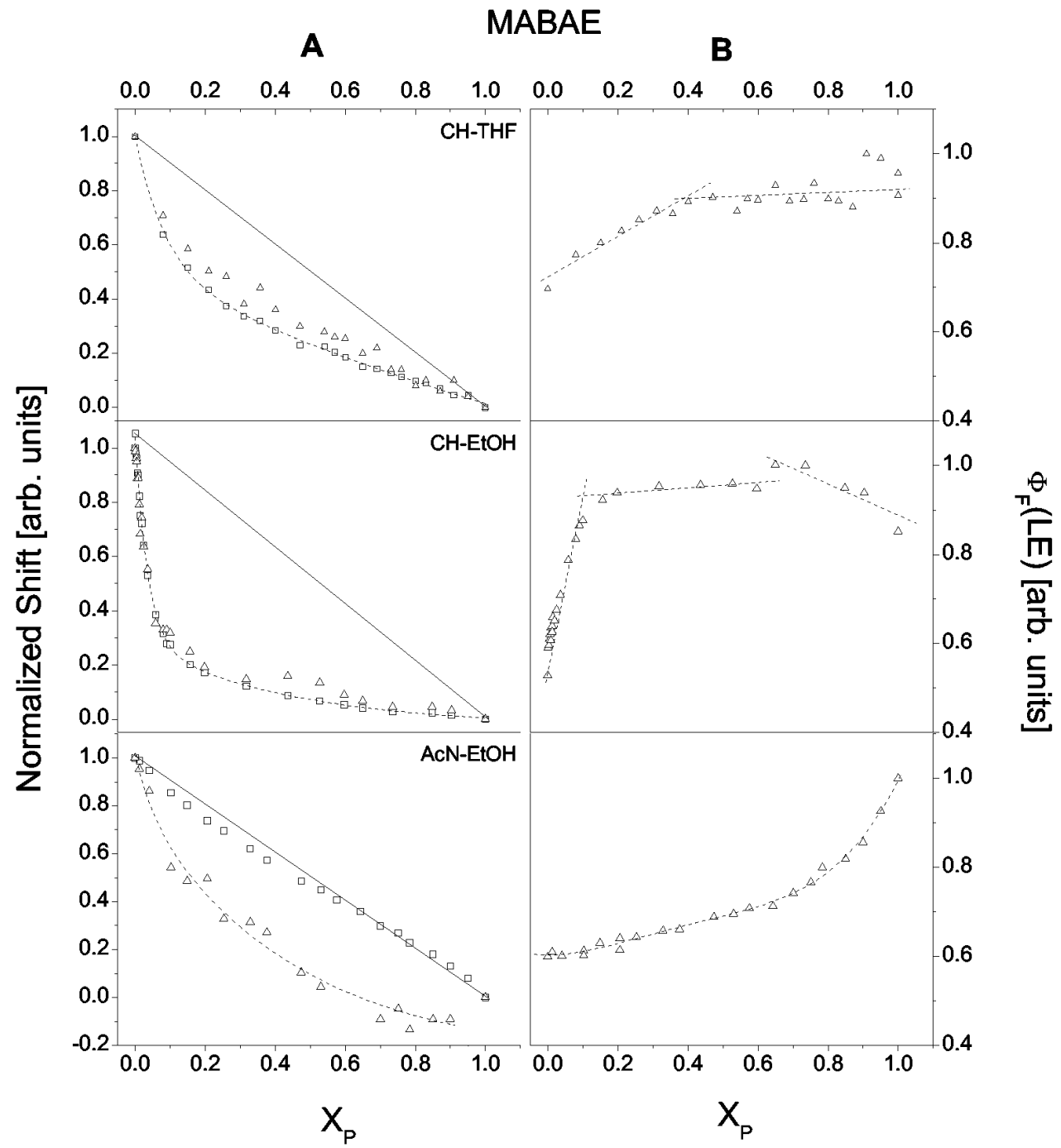

Fig. 6. Normalized solvatochromic shift of the absorption $(\square)$ and fluorescence $(\triangle)$ band maxima (A) and relative fluorescence quantum yield $\Phi_{\mathrm{LE}}(\mathrm{B})$ of MABAE in binary solutions vs. mole fractions $x_{\mathrm{p}}$, of THF and EtOH.

creasing concentration of THF or EtOH in $\mathrm{CH}$ solution. At high concentration of $\mathrm{EtOH}$, the fluorescence is quenched as a result of the formation of hydrogenbonding complexes. This process is very efficient for both molecules and is responsible for the preferential solvation, where each molecule of the protic component presumably enters the first solvation shell of the solute leading to a formation of $\mathrm{HB}$ complexes. A small addition $\left(x_{\mathrm{p}}<0.1\right)$ of protic molecules $(\mathrm{EtOH})$ to the nonpolar solution increases rapidly the normal fluorescence of MABAE (see panel 2, Fig. 6B) and the intensity of the ICT state fluorescence band of MDABAE. For the latter molecule, the normal fluo- rescence emission is quenched all times, whereas that from the ICT state for EtOH concentrations $x_{\mathrm{p}}>0.1$. The intensity increase of the fluorescence ICT band is induced by the hydrogen bond formation $[29,30]$.

\section{Summary}

The steady-state spectroscopic data of MABAE and MDABAE in neat and binary solvent mixtures were used to determine the influence of the specific (hydrogen bonds) and universal dipole-dipole interaction on a solvatochromic shift and an outer/inner reorganization energy of the solute molecules. For the enti- 


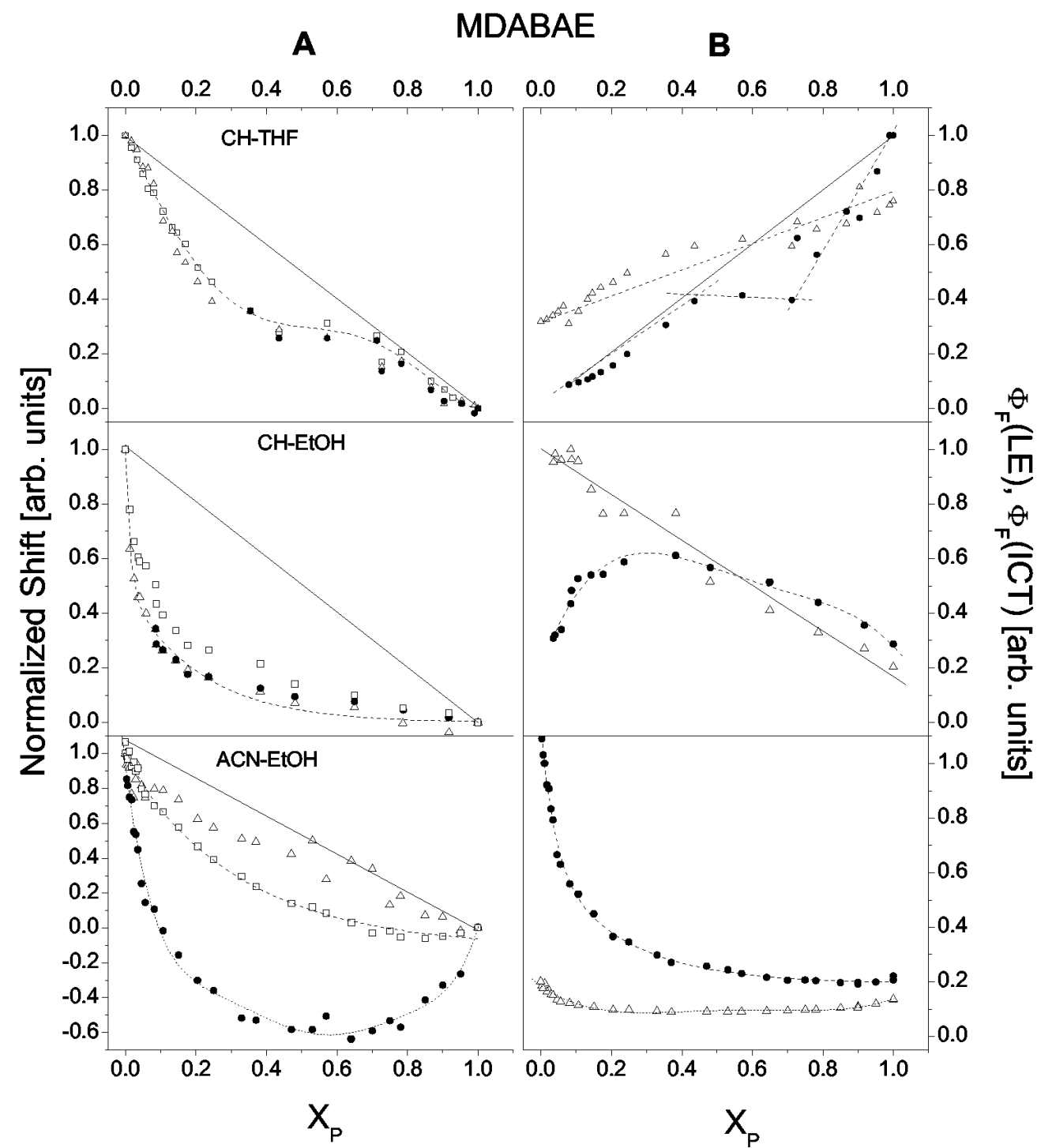

Fig. 7. Normalized shift of the absorption $(\square)$ and fluorescence $(\triangle$ LE; $\bullet$ ICT) band maxima (A) and relative fluorescence quantum yield $\Phi_{\mathrm{LE}}(\triangle)$ and $\Phi_{\mathrm{ICT}}(\bullet)(\mathrm{B})$ of MDABAE in binary solutions vs. mole fraction $x_{\mathrm{p}}$ of THF and EtOH.

tled molecules the permanent electric dipole moment has been determined in the $\mathrm{S}_{0}, \mathrm{~S}_{1}$ (LE) and $\mathrm{S}_{1}$ (TICT) states. The multiple linear regression of Kamlet et al. has been used to correlate the absorption and fluorescence wavelength maxima with an index of the polarizability $\pi^{*}$, and the $\alpha$ and $\beta$ values representing the hydrogen bond donating and accepting ability, respectively, of the studied molecules. The energy of the absorption and fluorescence transition is mostly determined by the dipolar interaction $\left(\pi^{*}\right)$ and hydrogen bond accepting $(\beta)$ ability of the solvent. An ex- ception is the absorption energy of MDABAE, where the hydrogen donation $(\alpha)$ ability plays a significantly greater role.

The determined normalized solvatochromic shifts of the absorption and fluorescence LE and ICT bands of the molecules under study in binary mixed solvents indicate a pronounced bigger shift at low concentration of the polar-protic component in comparison to that at higher $\mathrm{x}_{\mathrm{p}}$ values and that of a polar aprotic ingredient. The intensity changes of fluorescence LE and ICT bands indicate that in the $\mathrm{CH}-\mathrm{EtOH}$ binary mix- 
ture hydrogen bond complexes are formed, they enhanced emission from the $\mathrm{S}_{1}$ (LE) state. In CH-THF binary mixtures both emission modes are enhanced by increasing concentration of THF.

Time-resolved spectroscopic studies, which are in progress, will give a deeper insight in the solvation processes in neat and binary mixed solvents of the entitled molecules.

[1] D. Gormin, J. Phys. Chem. 93, 5979 (1989).

[2] D. Gormin and M. Kasha, Chem. Phys. Lett. 153, 574 (1988).

[3] J. Heldt, D. Gormin, and M. Kasha, Chem. Phys. 136, 321 (1989).

[4] D. Gormin, J. Heldt, and M. Kasha, J. Phys. Chem. 94, 1185 (1990).

[5] Z.R. Grabowski, K. Rotkiewicz, A. Siemiarczuk, D. J. Cowley, and W. Baumann, Nouv. J. Chim. 3, 443 (1979).

[6] Z. R. Grabowski, K. Rotkiewicz, and W. Rettig, Chem. Rev. 103, 3899 (2003) and references therein.

[7] A. Morimoto, L. Biczok, T. Yatsuhashi, T. Shimada, S. Baba, H. Tachibana, D. A. Tryk, and H. Inoue, J. Phys. Chem. A 106, 10089 (2002).

[8] K. A. Zachariasse, Th. von der Haar, A. Hebecker, U. Leinhos, and W. Kuehnle, Pure Appl. Chem. 65, 1745 (1993).

[9] K. A. Zachariasse, M. Grobys, Th. von der Haar, A. Hebecker, Yu. V. Il'iechev, Y.-B. Jiang, O. Morawski, and W. Kuehnle, J. Photochem. Photobiol. A. Chem. 102, 59 (1996).

[10] U. Leinhos, W. Kuehnle, and K. A. Zachariasse, J. Phys. Chem. 95, 2013 (1991).

[11] D. Pilloud, P. Suppan, and L. van Haelst, Chem. Phys. Lett. 137, 130 (1987).

[12] T. Okada, U. Makoto, G. Koehler, K. Rechthaler, K. Rotkiewicz, W. Rettig, and G. Grabner, Chem. Phys. 241, 327 (1999).

[13] J. Heldt, J. Photochem. Photobiol. A. Chem. 60, 183 (1991).

\section{Acknowledgements}

This work was partially supported by the research grant BW 5200-5-0162-5 of the University of Gdańsk. The authors wish to thank Prof. Józef Heldt for discussion and comments on the manuscript.

[14] J. Heldt, D. Gormin, and M. Kasha, Chem. Phys. Lett. 150, 433 (1988).

[15] Y. Oshika, J. Phys. Soc. Jpn. 18, 594 (1954).

[16] E. Lippert, Z. Elektrochem. 61, 962 (1957).

[17] L. Bilot and A. Kawski, Z. Naturforsch. 17a, 621 (1962).

[18] A. Kawski, Progress in Photochemistry and Photophysics, Vol. 5 (Ed. J. F. Rabek), CRC Press, Boca Raton, USA 1992, Chapter 1, pp. 1- 47.

[19] M. J. Kamlet, J.L. M. Abboud, M. H. Abraham, and R. W. Taft, J. Org. Chem. 48, 2877 (1983).

[20] M. J. Kamlet, Prog. Phys. Org. Chem. 13, 485 (1981).

[21] B. S. Brunschwig, S. Ehrenson, and N. Sutin, J. Phys. Chem. 91, 4714 (1987).

[22] H. Grudzinski and J. Heldt, Acta Phys. Polon. 25, 391 (1964).

[23] B.S. Neporent and N. G. Bakshiev, Opt. Spectrosc. 5, 634 (1958).

[24] N. G. Bakshiev, Opt. Spectrosc. 13, 507 (1966).

[25] N. Mataga and T. Kubota, Molecular Interactions and Electronic Spectra, Marcel Dekker Inc., New York 1970, Chapter 8.

[26] M. J. S. Dewar, E. G. Zoebisch, E. F. Healy, and J. J. P. Stewart, J. Am. Chem. Soc. 107, 3902 (1985).

[27] J. J. P. Stewart, J. Comp. Chem. 10, 209 (1989).

[28] P. Suppan, J. Photochem. Photobiol. A 50, 293 (1990).

[29] W.-M. Kwok, M. G. George, D. C. Grills, C. Ma, P. Matusek, A. W. Parker, D. Phillips, W. T. Toner, and M. Towrie, Angew. Chem. Int. Ed. 42, 1826 (2003).

[30] Y.H. Kim, D.W. Cho, N.W. Song, D. Kim, and M. Yoon, J. Photochem. Photobiol. A Chem. 106, 161 (1997). 